\title{
Smart Garbage Monitoring System for Waste Management
}

\author{
Norfadzlia Mohd Yusof ${ }^{1, *}$, Aiman Zakwan Jidin ${ }^{1}$, and Muhammad Izzat Rahim ${ }^{1}$ \\ ${ }^{1}$ Faculty of Engineering Technology, Universiti Teknikal Malaysia Melaka, Malaysia
}

\begin{abstract}
Piles of rubbish are one of the major problems faced by most people in Malaysia, especially those who live in flats, as the number of bins is limited and shared among all residents. It may cause pollutions, which may lead to sanitary issues and diseases. This project presents the development of a smart garbage monitoring system in order to measure waste level in the garbage bin in real-time and to alert the municipality, in particular cases, via SMS. The proposed system is consisted by the ultrasonic sensor to measure the waste level, the GSM module to send the SMS, and an Arduino Uno which controls the system operation. It supposes to generate and send the warning messages to the municipality via SMS when the waste bin is full or almost full, so the garbage can be collected immediately. Furthermore, it is expected to contribute to improving the efficiency of the solid waste disposal management.
\end{abstract}

\section{Introduction}

Nowadays, there are tons of flats and apartments which have been built in the rapid urbanization area. This is due to high housing demands which have been drastically risen as a result of migration from villages to cities to find works. In order to accommodate the growing population in the urban area, the government has built flats, apartments or condominiums, to provide shelter for them. Besides, flats become popular mainly in the United State, Europe and other developing countries [1, 2].

There are several issues faced by the inhabitants of the flats. One of them is the issue of the domestic solid waste disposal, which cause pollutions [3]. Unlike landed houses, the flats' waste disposal bins are shared among all residents which live in the same building, and thus, the bins tend to be filled very quickly. Thus, an unsystematic and inefficient disposal waste management may cause the bins to be always full with of garbage, and further littering from the residents will cause the garbage piles to be scattered outside the bins. Therefore, there will be a question of sanitary as those garbage piles may become the root cause of illness and diseases like dengue, diarrhea, and cholera.

Besides, there are also problems regarding the attitudes of each inhabitant of the flats. There are cases where some irresponsible residents, who normally live at the higher levels of the building, littered or simply threw their domestic waste directly from the floor which

\footnotetext{
* Corresponding author: norfadzlia@utem.edu.my
} 
they live into the bins. This may cause pollutions if the garbage thrown fell outside the bins or injuries to innocent people downstairs if they fell onto them.

The waste disposal can be managed more properly and efficiently by constantly monitoring the bin status and the garbage level [4]. In addition, the municipality can be alerted when the bin is full or almost full, thus promoting dynamic scheduling and routing of the garbage collection. By comparing to the conventional static scheduling and routing, this dynamic scheduling and routing are said to allow operational cost reduction, by reducing the number of trucks, the manual labour cost and the transport mileage savings [5, $6,7]$.

This paper presents an alternative in managing domestic waste especially in flat areas via a smart garbage monitoring system, which is developed based on Arduino Uno. This system will automatically monitor the garbage level at each bin and will alert the municipality in the case where the bins are almost full.

\section{Research methodology}

\subsection{System architecture}

Fig. 1 describes the block diagram of the monitoring system. It consists of several ultrasonic sensors, the Arduino Uno microcontroller, and the GSM module. The ultrasonic sensors are used to detect the level of garbage in each bin, and it will send this information to the Arduino Uno, which acts as the system controller. In the case where the bins are already full or almost full, then it will generate a warning message which will be sent to the municipality via SMS, by using the GSM module. Moreover, this system is also connected to several LEDs, in green or red colours, in order to alert all the residents regarding the bin status.

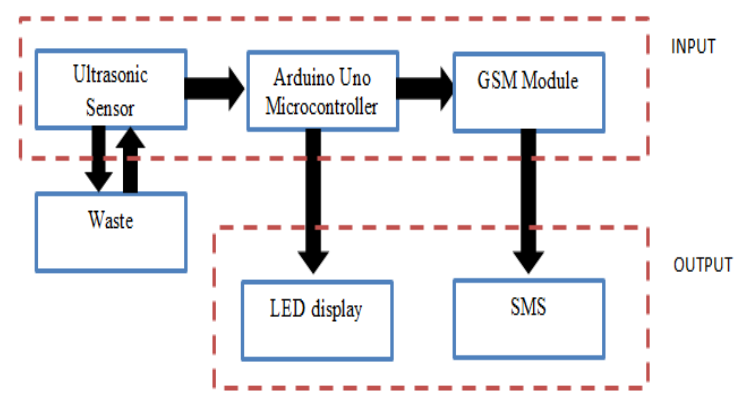

Fig. 1. Waste Management Monitoring System Block Diagram

\subsection{System process flow}

At first, the level or the height of the garbage in each bin is measured by using the ultrasonic sensor. This information is then received and processed by the Arduino Uno. It will determine whether the garbage level has been surpassing the threshold level or not. For this research purpose, there are two threshold levels sets: the first threshold is at $70 \%$ of the bin height, and the second threshold is set at $90 \%$ of the bin height.

If the garbage level in the bin is crossing the first threshold level, then the first warning message is generated and sent to the municipality. Besides, the green LEDs will be turned $\mathrm{ON}$ in order to alert all the residents at every floor. Next, if the garbage level in the bin is 
crossing the second threshold level, then the second warning message is generated and sent to the municipality. In this case, all the residents will be alerted when the red LEDs are turned $\mathrm{ON}$.

\section{Results and discussions}

Fig. 2 shows the hardware connection setup for the system. An Arduino Uno board is connected to the HC-SR04 ultrasonic sensor via digital I/O pin. Besides, the SIM900A GSM Module is serially connected to the Arduino Uno board, where the TX port of the GSM Module is connected to the RX port (PIN 2) of the Arduino Uno, while RX port of the former is tied to the TX port (PIN 3) of the latter. Moreover, a green LED and a red LED are also connected to the Arduino Uno.

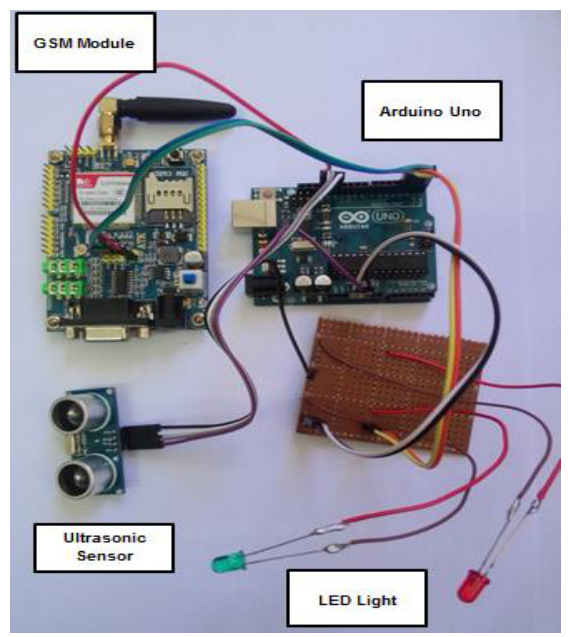

Fig. 2. All connection component of hardware in this system

The first test conducted is the situation where the garbage bin is empty or its garbage level is very low. As can be observed in Fig. 3, neither the green LED nor the red LED is turned on.

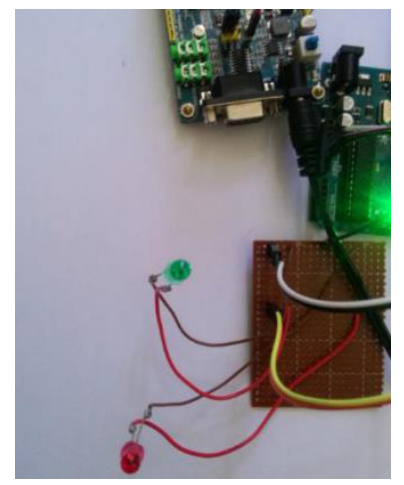

Fig. 3. Both LEDs are turned OFF. 
Then, the bin is filled with more garbage until its level has surpassed the first threshold value, which is set to $70 \%$. Fig. 4 shows that the green LED is turning ON, and then the first warning SMS is being sent, as depicted in Fig. 5.

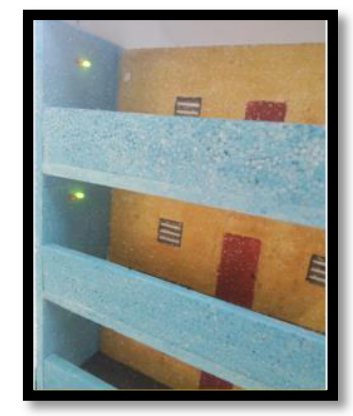

Fig. 4. GREEN LED is turned ON once the waste reaches the level of $70 \%$ full.

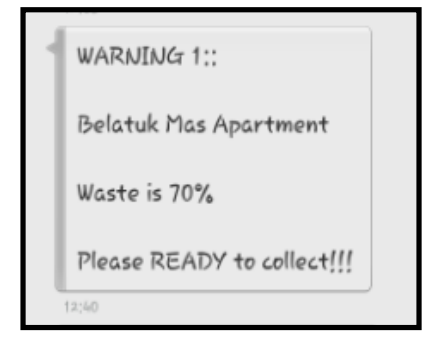

Fig. 5. The first notification SMS sent by the system, once the waste reaches the level of $70 \%$ full.

Next, the bin is fully filled and thus, the garbage level is now exceeding the second threshold level, which is set to $90 \%$ of the bin height. As the consequences, the red LED is now turning ON while the green LED is turned OFF, and the second warning SMS is sent, telling the municipality to immediately collect the waste disposal. This is shown in Fig. 6 and Fig. 7, respectively.

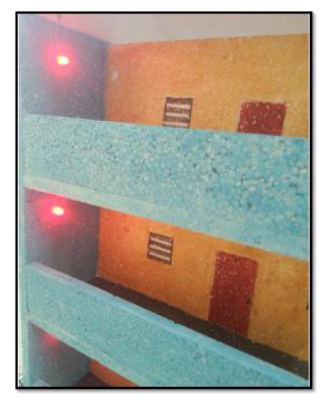

Fig. 6. Red LED is turned ON once the waste reaches the level of $70 \%$ full. 


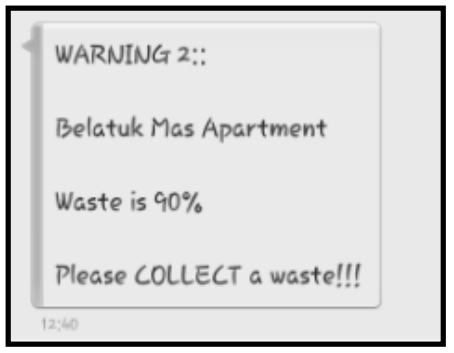

Fig. 7. The second notification SMS sent by the system, indicating that bin is at least $90 \%$ full and the garbage needs to be collected immediately.

\section{Conclusions}

This paper has described the development of a smart garbage monitoring system, which is based on Arduino Uno microcontroller. It is very useful in improving the efficiency of solid waste disposal management especially in the flat residential areas, where the garbage piles at the bins are one of the residents' major concerns owing to its ability to continuously measure the garbage level in the bin and alerting the municipality for immediate collection. The outputs from the conducted tests show that all the functionality of the system has performed correctly. The proposed system is suitable to be implemented in all flat residential areas, due to its practicality, reliability and reasonable cost.

The authors wish to acknowledge Universiti Teknikal Malaysia Melaka (UTeM) for the financial funding and providing instrumentation devices support of this project.

\section{References}

1. P. Sukholthaman, K. Shirahada, Proceedings of PICMET'14 Conference: Portland International Center for Management of Engineering and Technology; Infrastructure and Service Integration, (2014)

2. C. K.M. Lee, T. Wu, International Conference on Industrial Engineering and Engineering Management, 798 (2014)

3. A.F. Thompson, A.H. Afolayan, E.O. Ibidunmoye, Information Science, Computing and Telecommunications, 206 (2013)

4. M.A. Hannan, M. Arebey, R.A. Begum, H. Basri, Waste Manage., 32, 2229 (2012)

5. M.A.A.Mamun, M.A. Hannan, A. Hussain, H. Basri, IEEE Sensors Journal, 15, 561 (2015)

6. H. Krikke, I.L. Blanc, M. van Krieken, H. Fleuren, Int. J. Prod. Econ., 111, 209 (2008)

7. O. M. Johansson, Waste Manage., 26, 875 (2006) 